\title{
LA PARTICIPACIÓN INDÍGENA EN LA ACTIVIDAD TURÍSTICA EN TERRITORIO BRÖRÁN-TÉRRABA, COSTA RICA, 2018
}

Revista Trama Volumen 9, número 1

Enero - Junio 2020

Páginas 171-209

ISSN: 1659-343X

https://revistas.tec.ac.cr/trama
Indigenous Participation In Tourism Activity At Brörán-Térraba Territory, Costa Rica, 2018

Rodrigo Murillo Masís ${ }^{1}$

Yuliana Ruiz Umaña ${ }^{2}$

Fecha de recepción: 7 de noviembre, 2020

Fecha de aprobación: 13 de junio, 2020

Murillo, R. y Ruiz, Y. (2020). La participación indígena en la actividad turística en territorio Brörán-Térraba, Costa Rica, 2018. Trama, Revista de ciencias sociales y humanidades, Volumen 9, (1), Enero-Junio, págs. 171-209.

DOI: https://doi.org/10.18845/tramarcsh.v9i1.5273

1. Estudiante de Gestión de Turismo Sostenible. Instituto Tecnológico de Costa Rica, Escuela de Ciencias Sociales. Cartago, Costa Rica.

Correo electrónico: murillomasis@gmail.com

ORCID: https://orcid.org/0000-0003-2381-9919

2. Estudiante de Gestión de Turismo Sostenible. Instituto Tecnológico de Costa Rica, Escuela de Ciencias Sociales. Cartago, Costa Rica.

Correo electrónico: yulliana.ruiz.uma@gmail.com

ORCID: https://orcid.org/0000-0002-6047-7949 


\section{Resumen}

En el territorio indígena Térraba, ubicado en la provincia de Puntarenas en Costa Rica, su pueblo participa en el desarrollo del turismo a través de prácticas que no tengan un mayor impacto en la naturaleza y que no implique una pérdida de su cultura. Diversos estudios indican que la población indígena costarricense sufre altos niveles de desigualdad, y además, cuentan con menores tasas de participación en la economía. El trabajo analiza mediante un método cualitativo y de carácter etnográfico, por medio de las técnicas de entrevistas a profundidad y observación participante cómo las iniciativas de turismo, pueden ser ejemplo en la organización de actividades económicas y el empoderamiento para el desarrollo de comunidades indígenas. La principal conclusión de este trabajo indica que para la gestión del turismo sostenible ha sido fundamental una participación crítica por parte de los indígenas de la asociación Mano de Tigre, el Descanso y el Rincón Ecológico dentro de la comunidad Bröran. Se recomienda optimizar los servicios y ofertar el destino ya que cuenta con un alto potencial turismo nacional e internacional.

Palabras clave: empoderamiento; turismo y sociedad; desigualdad.

\section{Abstract}

In the Térraba indigenous territory, located in the province of Puntarenas in Costa Rica, its people participate in the development of tourism through practices that do not have a major impact on nature and that do not imply a loss of their culture. Various studies indicate that Costa Rica's indigenous population suffers from high levels of inequality, and they also have lower rates of participation in the economy. The work analyzes through a qualitative and ethnographic method, through the techniques of in-depth interviews and participant observation how tourism initiatives can be an example in the organization of economic activities and empowerment for the development of indigenous communities. The main conclusion of this work indicates that critical participation by the indigenous people of the association Mano de Tigre, el Descanso y el Rincón Ecológico within the Bröran community has been fundamental to the management of sustainable tourism. It is recommended to optimize the services and offer the destination as it has a high potential for national and international tourism.

Keywords: empowerment; tourism and society; inequality. 


\section{INTRODUCCIÓN}

El turismo a nivel de Costa Rica ha venido en constante crecimiento y ha sido un generador de oportunidades laborales para la población nacional e internacional. Los tipos de turismo en el país han permitido adaptarse y crear nuevas ofertas para la demanda actual de turistas que ingresan diariamente a realizar distintos tipos de actividades, como es la visita a sitios turísticos de interés cultural. Al respecto, el turismo indígena consiste en brindar una experiencia "auténtica" al turista, en la cual se vive la cultura, aprende de la cosmovisión, espiritualidad y la relación con la naturaleza (Umaña, 2017). Es el tipo de turismo que toma fuerza a través de emprendimientos comunitarios que contribuyen a la economía local, protección del entorno natural y da a conocer la cultura autóctona.

Este artículo se deriva de una investigación realizada en 2018 en el pueblo indígena de Térraba, en Costa Rica, ubicado en el cantón de Buenos aires de Puntarenas. Para ello, se realiza un diagnóstico de los emprendimientos turísticos la Asociación Mano de Tigre, el Descanso y Rincón Ecológico, así como un análisis de las condiciones organizativas.

Del mismo modo, se busca determinar las condiciones organizativas de las iniciativas de turismo que operan en la comunidad Brörán - Térraba y su relación con la gestión del turismo sostenible en sus territorios. Para lograr los objetivos, se realizó trabajo el campo en ese territorio. La metodología aplicada consiste en la observación, entrevistas a los distintos líderes a cargo de los emprendimientos y la revisión bibliográfica.

El contexto en el cual se desarrolla el trabajo son las luchas por sus derechos en cuanto a territorio y las dificultades que han tenido en la comunidad de Térraba. Por lo tanto, se explica el contexto social en referencias historias contadas por los mismos actores sociales y la relación que esto ha tenido con el turismo, así como la forma de gestionar un turismo indígena sostenible. La investigación se realizó dentro de un marco de respeto hacia la comunidad estableciendo una relación donde se pretende escuchar y realizar un diagnóstico con el permiso previo de la comunidad para la recopilación de la información con fines académicos. 


\section{ANTECEDENTES}

En el Plan Nacional de Desarrollo Rural 2015 - 2020, realizado por el Instituto de Desarrollo Rural, encontramos los datos sobre la organización administrativa del territorio, específicamente sobre el cantón de Buenos Aires:

El cantón de Buenos Aires, perteneciente a la provincia de Puntarenas, fue erigido mediante la a Ley 185, de 29 de Julio de 1940, con cinco distritos y designado como cabecera de la villa. Luego se crearon cuatro distritos más: Colinas, Chánguena en 1988, Biolley en 1995 y Brunka en el año 2000 [...] El cantón de Buenos Aires, el cual tiene una extensión territorial de 2384,2 km2 está compuesto por nueve distritos: Buenos Aires, Volcán, Potrero Grande, Boruca, Pilas, Colinas, Chánguena, Biolley y Brunka"[...] Los cantones Buenos Aires y Coto Brus, albergan cinco grupos étnicos (denominados pueblos) y siete Territorios Indígenas, ocupando distintas áreas de su territorio (INDER 2010).

Entre los principales problemas que enfrenta la población indígena en estos territorios se encuentra la dificulta para iniciar actividades productivas generadoras de empleo e ingresos a sus familias. Lo anterior se debe a varios factores, entre ellos: la falta de conocimientos en aspectos técnicos (sobre desarrollo de capacidades) e informativos (sobre aspectos de procedimientos propios de la institucionalidad costarricense); la disponibilidad de herramientas que les permitan a diferentes grupos generacionales como jóvenes, mujeres, personas adultas mayores desarrollar proyectos productivos que permitan una mejor condición de vida y; la falta de acceso a créditos para la producción. Asimismo, destaca la dificultad de acceso a los servicios públicos, debido al aislamiento geográfico y a la falta de vías de comunicación; existencia de altos índices de pobreza; altos porcentajes de analfabetismo; difícil acceso tanto a la educación secundaria como a la universitaria y; escasos servicios en salud, debido a la escasez de programas institucionales adaptados a las condiciones de los pueblos indígenas; entre otros (INDER, 2010). 
Imagen 1. Mapa del cantón de Buenos Aires, Puntarenas.

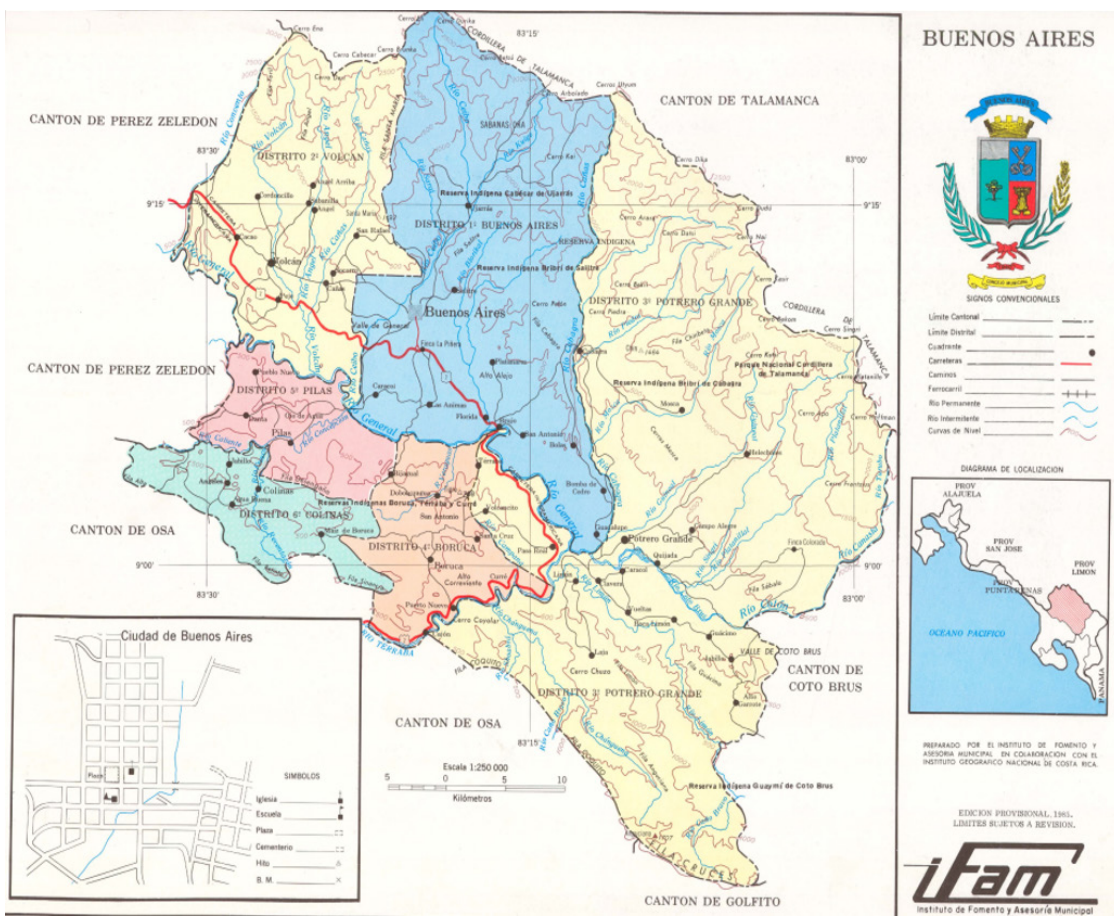

Fuente: Instituto de Fomento y Asesoría Municipal, 1985.

La comunidad de Térraba cuenta con una historia de luchas por razones de propiedad territorial, venta de territorio a personas no indígenas y la imposición por parte del Estado costarricense de la Asociación de Desarrollo Integral (ADI). Esta es un organismo con autoridad político-formal implantada dentro de los pueblos indígenas que cuenta con la participación mayoritaria de personas no indígenas. Ello amenaza su legado cultural y económico, la participación y el derecho de estos pueblos a decidir sobre sus propias prioridades de desarrollo, en la medida que este afecte a sus vidas, creencias, instituciones, bienestar espiritual y las tierras que ocupan o utilizan de alguna manera. En su mayoría, las tierras en el Valle de Diquís se encuentran en manos de no indígenas.

La Ley Indígena, declarada en el año 1977, establece que los territorios indígenas (aquellas áreas tituladas a los pueblos indígenas 
que por lo general no abarcan el territorio tradicionalmente poseído) son inalienables, imprescriptibles, no transferibles y exclusivas para los pueblos indígenas.

La zona, de gran riqueza biológica, posee el río Grande de Térraba, que es el más largo del país y atraviesa tierras muy fértiles y en su desembocadura con el mar posee uno de los humedales más grandes de Costa Rica (Dittel, 2015). El planteamiento, indica que la zona es un gran atractivo para el turismo y para inversionistas.

La economía tradicional de los Térraba se basa en las actividades agrícolas y de pesca de subsistencia, principalmente utilizando los recursos de sus bosques y aguas. En la década de 1970, el Estado promovió la conversión de los bosques a tierras de agricultura y pastoreo. Por esta razón, mucho del bosque de los Térraba se perdió. Su habilidad para practicar y beneficiarse de su economía tradicional se redujo drásticamente en los años siguientes como consecuente de la ocupación de sus tierras por no indígenas. Actualmente, se les niegan la posibilidad de practicar y beneficiarse de su economía tradicional y han sido forzados a participar en la economía capitalista (Habtom, 2010.pág. 3).

En referencia al turismo existente en la zona, se da dentro de las áreas de manejo comunitario, y prevé la protección y conservación de recursos naturales como las fuentes de agua mediante la reforestación, como es la llevada a cabo por el emprendimiento Rincón Ecológico. Del mismo modo, se considera el fortalecimiento y el fomento del Etnoturismo, el cual refuerza la cultura Térraba, principalmente por el uso de tradiciones que se practican en el territorio, como la producción de artesanías, la preparación de bebidas y comidas, así como la agricultura orgánica amigable con el medio ambiente. Todas estas actividades vienen a generar ingresos económicos, contribuyendo con la disminución de la pobreza existente en la comunidad, así como el mejoramiento a mediano y largo plazo del medio ambiente (Sánchez, 2016). 


\section{IMPORTANCIA ECONÓMICA DEL TURISMO}

Según el Barómetro de la Organización Mundial del Turismo 2018 (OMT, 2018), 1 de cada 10 empleos a nivel mundial son de turismo, que a su vez genera 1,6 billones de dólares estadounidenses en exportaciones. Representa un $10 \%$ del PIB mundial y un $7 \%$ de las exportaciones mundiales, que es un $30 \%$ de las exportaciones en servicios.

En Costa Rica, los datos del Instituto Costarricense de Turismo (ICT, 2018), indican que se ha presentado una tendencia en aumento desde el año 2010 en cuanto a las divisas por concepto del turismo en el país, siendo en ese año, 2233,5 millones de dólares estadounidenses y en el 2017, 3864,1 millones de dólares. Estando por encima que la generación de divisas por café y banano. Esto representó para el 2017 un 6,7\% del PIB de Costa Rica y un $35,4 \%$ de las exportaciones. 


\section{JUSTIFICACIÓN}

En Costa Rica, las condiciones de desigualdad y exclusión social específicamente de los grupos indígenas originarios es manifestada como el impedimento del goce de los derechos y desarrollo humano. Según el Programa de las Naciones Unidas para el Desarrollo (2017) en Costa Rica el 70,1\% de los hogares en territorios indígenas tiene al menos una necesidad básica insatisfecha, en comparación a un $26,4 \%$ a nivel nacional.

Del mismo modo con el paso del tiempo, la comunidad Térraba se ha visto involucrada en una lucha constante por la recuperación de su territorio, el cual en fue adquirido ilegalmente por personas no indígenas,

Con la implementación del etnoturismo ha diso importante tomar en cuenta los territorios indígenas. Por lo tanto, es importante conocer cuáles son los actuales proyectos y factores que han condicionado la formación y sostenibilidad de estos; específicamente en el contexto de la recuperación de sus tierras dentro de la comunidad.

El despojo de los territorios indígenas demuestra problemas importantes en las condiciones de desigualdad, violencia e inacción del Estado hacia estas poblaciones. En este contexto, sin embargo, el turismo para la comunidad de Térraba Brörán se convierte en una alternativa económica que busca una relación armónica entre la cosmovisión indígena, el ambiente y la generación de capital para su subsistencia.

Las planificaciones turísticas de los proyectos existentes están enmarcadas dentro del concepto de etnoturismo, que consiste en aquel tipo de turismo destinado a relacionarse con las comunidades indígenas y conocer culturas y tradiciones.

Dentro del marco del etnoturismo, la dimensión ambiental es fundamental la relación entre lo humano y el entorno natural, pues esta es esencial dentro de la cosmovisión de los pobladores de la región. Al respecto, los indígenas indican que sin el bosque no tendría sentido su existencia y que es parte de ellos. Además, el ejemplo del Rincón Ecológico denota que la recuperación de bosque dentro del territorio ha sido significativa y ha formado parte de los tours que se practican actualmente. 
En el territorio indígena Térraba, la comunidad ha liderado emprendimientos turísticos con el fin de beneficiarse de manera económica, social, ambiental y cultural. Estos emprendimiento utilizan su principal recurso cultural para dar a conocer y rescatar sus raíces.

Por tanto, este trabajo tiene como objetivos:

- Explorar las condiciones organizativas que presentan los emprendimientos turísticos, la Asociación Mano de Tigre, el Descanso y Rincón Ecológico, en la comunidad Brörán - Térraba.

- Identificar desde la perspectiva de las organizaciones indígenas locales, su relación con la Gestión del Turismo Sostenible. 


\section{MARCO TEÓRICO}

La Organización Mundial del Turismo (2018) define Turismo en su glosario básico como:

un fenómeno social, cultural y económico relacionado con el movimiento de las personas a lugares que se encuentran fuera de su lugar de residencia habitual por motivos personales o de negocios/ profesionales. Estas personas se denominan "visitantes" (que pueden ser turistas o excursionistas; residentes o no residentes) y el turismo tiene que ver con sus actividades, de las cuales algunas implican un gasto turístico.

De la mano del turismo y el aprovechamiento del tiempo libre aparece el ocio, que Gutiérrez de Calderón propone de la siguiente manera "Si definimos el ocio como "el empleo creativo y productivo, desde el punto de vista emocional, del tiempo libre" nos damos cuenta que, sin duda, Turismo y Ocio son dos caras de una misma moneda." (Gutiérrez de Calderón, 2003)

Asimismo, se habla de desarrollo sostenible como el impacto que tiene este sobre las actividades que se realizan todos los días y se utiliza como solución a la problemática que se enfrenta en temas referentes al ambiente o como sinónimo de actividades amigables con la naturaleza.

Podemos decir que desarrollo sostenible "es lo que permita a las generaciones presentes satisfacer sus necesidades sin comprometer las capacidades de las generaciones futuras para satisfacer sus propias necesidades, como un elemento básico para alcanzar la superación de las condiciones de pobreza" (Marín, García y Daltabuit, 2012). Entonces con esto comprendemos que desarrollo sostenible es un concepto antropocentrista que busca conservar en función de las futuras necesidades humanas.

Ahora bien, habrá que aclarar necesariamente que este desarrollo sostenible va de la mano con un proyecto económico mundial que es la implementación del neoliberalismo en los países en vías de desarrollo. Esta vez con las prescripciones del capitalismo con "rostro humano" y los organismos financieros internacionales es que surgen los términos de desarrollo sostenible, siendo su aplicación ejercida otra vez desde los países de primer mundo: 
Se buscará, se dijo, el crecimiento económico de los países pobres cuidando los recursos naturales y culturales de que disponen; la mejor manera de conservarlos será aprovechándose racionalmente. Desde luego, el aprovechamiento se planteó a partir de la aplicación de la racionalidad capitalista (Monterroso, 2011: p. 284).

La intersección del desarrollo sostenible y el turismo nos lleva a considerar que es necesario definir qué es el Turismo Sostenible, no solo por ser parte de nuestro problema de investigación, sino que creemos que es importante generar un acercamiento a la construcción de un concepto el cual podamos utilizar, ya que se ha vuelto de uso común inclusive por la demanda pero que, muchas veces, no podemos decir en simples palabras qué es. Según la Organización Mundial del Turismo (2018), el turismo sostenible es "el turismo que tiene plenamente en cuenta las repercusiones actuales y futuras, económicas, sociales y medioambientales para satisfacer las necesidades de los visitantes, de la industria, del entorno y de las comunidades anfitrionas".

A nivel nacional el tema ha venido en crecimiento y se ha manejado una noción a nivel empresarial nacional. También se ha generado una búsqueda en posicionarse por parte del Instituto Costarricense deTurismo a nivel internacional como uno de los referentes en sostenibilidad.

El Sistema Nacional de Áreas de Conservación (SINAC) realizó un cuaderno de trabajo donde escribe:

Una de las principales responsabilidades de una empresa $u$ organización dedicada a actividades turísticas es valorar el patrimonio social y cultural como un componente importante del producto turístico de una región. [...] Generalmente, las iniciativas turísticas están insertas en zonas cuyas poblaciones se encuentran interesadas en el desarrollo turístico. Para garantizar un marco de respeto, las comunidades locales deben estar involucradas en todo el proceso de desarrollo turístico, desde la planificación hasta la gestión de los productos, a fin de lograr los máximos beneficios económicos, ecológicos y socioculturales [...] La iniciativa turística está en la responsabilidad de promover el respeto por las culturas y poblaciones locales, y brindar consejos a los visitantes sobre cómo comportarse adecuadamente en las comunidades visitadas (Hurtado, 2015). 


\section{Este se puede contrastar con la evolución del concepto de Turismo Sostenible que nos presenta Ramírez (2015) a modo de tabla:}

Tabla 1. Evolución del concepto de turismo sostenible.

\section{Año}

Definición de Turismo Sostenible

En el marco del $41^{\circ}$ Congreso de la Asociación Internacional de Expertos Científicos en Turismo.

"El turismo sostenible es aquel que mantiene el equilibrio entre los intereses sociales, económicos y ecológicos".

Definición de turismo sostenible según Bolívar Troncoso, Vicepresidente del Consejo para el Desarrollo Sostenible y Promoción de la República Dominicana.

"Turismo sostenible es un estilo que busca en cada región soluciones específicas a problemas concretos tomando en consideración el entorno natural y cultural, atendiendo a las necesidades inmediatas y a las de largo plazo. Se trata de encontrar los medios de amortizar el desarrollo socioeconómico con un manejo adecuado de los recursos naturales y el medio ambiente".

Butler, R.

(n) "Un desarrollo en el que el turismo es promovido y mantenido en un área (comunidad y entorno) en una forma y a una escala tal que puede permanecer siendo viable por un periodo indefinido, al mismo tiempo que no altera el medio ambiente (humano y físico) en el cual se desenvuelve de modo que no impide el desarrollo y bienestar de otras actividades y procesos".

Conferencia Euro Mediterránea sobre Turismo y Desarrollo Sostenible "Tourism the year 2000 and beyond qualitative aspects".

m

"El Turismo Sostenible atiende a las necesidades de los turistas actuales y de las regiones receptorasy al mismo tiempo protege y fomenta las oportunidades para el futuro. Se concibe como una vía hacia la gestión de todos los recursos de forma que puedan satisfacerse las necesidades económicas, sociales y estéticas, respetando al mismo tiempo la integridad cultural, los procesos ecológicos esenciales, la diversidad biológica y los sistemas que sostienen la vida".

Capece, G. Turismo sostenible y sustentable, una visión holística. Buenos Aires.

"La actividad económica productora de bienes y servicios que, respetando los límites físicos del espacio en que se desarrolla y los p síquicos de los habitantes y demás a ctores, son destinados a quienes deciden desplazarse temporal y voluntariamente fuera del lugar de residencia habitual sin incorporarse al mercado de trabajo del lugar del destino, con motivo o no de recreación". 
Organización Mundial del Turismo (OMT):

La Organización Mundial del Turismo define al turismo sostenible como el que atiende las necesidades de los turistas actuales y de las regiones receptoras $y$, al mismo tiempo, protege y fomenta las oportunidades para el futuro.

Se concibe como una vía hacia la gestión de todos los recursos de forma que puedan satisfacerse las necesidades:

- Económicas

- Sociales

- Estéticas

Respetando la integridad cultural, los procesos ecológicos esenciales, la diversidad biológica y los sistemas que sostienen la vida (OMT, 1999).

Fuente: Ramírez Guerrero (2015).

Con lagestión del turismo sostenible tenemos entonces el problema de la apropiación en los recursos por parte de las comunidades. En este sentido, apropiación turística es aquel proceso por el cual las expresiones culturales de una sociedad, al ser intervenidas por diversos actores e instituciones, se transforman simbólicamente en mercancías turísticas, es decir, objetos de consumo que se ofertan dentro del mercado turístico. Sucede con recursos ecológicos, playas, manglares, ríos, bosques, selvas, paisajes naturales y agrarios, cultivos, flora y fauna que, modificando la actividad turística, se pueden llegar a ver alterados no solo físicamente, sino también de manera simbólica al ser resignificados en función del mercado turístico (Zúñiga, 2012).

Esta intervención debe tener en cuenta que a la hora de realizar una actividad turística generará impactos, tanto positivos como negativos. Entre los negativos algunos que son de suma importancia para este trabajo son la turismofobia, que Monterroso lo define como principal factor que define a una comunidad que está cansada de cumplir con la demanda del turismo extranjero, por la cantidad inmensa de infraestructura turística como los hoteles, restaurantes, aeropuertos, carreteras, sitios de recreación etc. Además de la pérdida de la identidad que los caracteriza como comunidad y cultura única (Monterroso, 2011). También se espera comprender si la etnicidad se ha vuelto un producto, 
es decir culturas textualizadas (Lagunas, 2012) o si es parte del diario vivir lo que se muestra sin actuaciones.

Estas actuaciones se ven reflejadas en las brechas reales y las irreales ofrecidas a los turistas con un panorama donde no ocurren conflictos, no hay niños pasando hambre, gente sin trabajo, en condiciones de explotación, de mercantilización de la cultura y se degrada el ambiente por su constante explotación. Como beneficios se obtienen efectos multiplicadores de trabajo e ingresos por la infraestructura turística que se establece (Lagunas, 2012).

Desde la ecología política, de manera crítica, se ha planteado que:

En la búsqueda por la sustentabilidad y la aplicación del turismo alternativo, la pérdida cultural y la implementación de turismo rural que despoja a los trabajadores rurales de su día a día para incluirlos en este proceso es que se empieza a hablar sobre la ecología política, "ciencia que permite el tratamiento de los variados aspectos que presenta la problemática ambiental y, fundamentalmente, ubicar los problemas ambientales como relaciones de poder" (Monterroso, 2011: $p$ 291).

En cuanto a la noción de organización, en este trabajo se entiende como:

La estructuración técnica de las relaciones que deben existir entre funciones, niveles yactividades de los elementos humanosymateriales de un organismo social, con el fin de lograr máxima eficiencia en la realización de planes y objetivos señalados con anterioridad (Gómez Ceja, 1994).

Se piensa en organización como: 1) La identificación y clasificación de las actividades requeridas, 2) El agrupamiento de las actividades necesarias para lograr los objetivos, 3) La asignación de cada agrupamiento a un administrador con la autoridad necesaria para supervisar (delegación) y 4) las medidas para coordinar horizontalmente y verticalmente en la estructura organizacional (Koontz y Weihrich, 1998) 


\section{METODOLOGÍA}

La metodología de este trabajo se llevó a cabo mediante un proceso de investigación exploratoria, de tipo cualitativo con un enfoque etnográfico, que busca por medio la observación participante y la entrevista a profundidad, alcanzar los objetivos propuestos: La descripción de los emprendimientos turísticos, con las correspondientes características y cómo se complementan los proyectos entre sí, para fortalecer el bien común de la comunidad. Desde un punto de vista ético, como investigadores en relación con los otros, nos alejamos de cualquier relación de supuesta superioridad académica y más bien nos enfocamos en la búsqueda de una horizontalidad y un diálogo de saberes.

El presente trabajo se encaminó a la búsqueda de información a través de fuentes de información primarias y secundarias que permitieron llegar a las conclusiones y cumplir con los objetivos planteados. Existen fuentes de información primaria que se recogen con la observación, asistencia a charlas, congresos, visitas, etc. Las fuentes de investigación secundarias son informaciones recogidas previamente de otras investigaciones, aportan conocimiento y son clasificadas con informes de censos y estadísticas, consumo y hábitos, bibliotecas, televisión, prensa, radio y estudios oficiales realizados en el campo del turismo.

El enfoque etnográfico se refiere al recurso privilegiado de comprensión de la unidad/alteridad de la especie humana que, puesto en práctica en el campo del turismo es el análisis de contextos que permiten hacer una comparación con la realidad etnográfica familiar. Así, se complementan temas de identidad, la migración, los mercados laborales, políticas de conservación de la naturaleza, territorio, estilos de vida, etc. De igual manera, se debe buscar enlazar la antropología en el turismo para buscar e indagar en la literatura de viajes y en aquellas obras que reflejan los conflictos de intereses entre diversos actores cuya convivencia está en el turismo. El antropólogo observa desde una perspectiva donde busca lo exótico (Guzmán, 2012).

Parte de las técnicas utilizadas son la observación, donde se vieron las actividades desarrolladas en la zona a través de un enfoque de la participación crítica, donde los espacios se construyen cooperativamente a través de la interacción (Salazar et al, 2011: p. 62), donde es de especial atención el diálogo para el desarrollo de la comunidad y el turismo. 
Entre las técnicas cualitativas utilizadas se encuentran el grupo de discusión que se llevó a cabo con personas que hablan sobre un tema y permite obtener información sobre el mismo, sobre todo para la creación de un nuevo producto o servicio. Además, se llevó a cabo una entrevista en profundidad aplicada a personas de la comunidad.

El análisis de la información se produjo con base en los datos recogidos a través de la observación participante y las grabaciones efectuadas con el consentimiento informado de las personas que fueron parte de esta investigación.

A través de la observación participante se realizó una visita a el lugar de estudio, y previamente se realizó una revisión bibliográfica. La observación se llevó a cabo en los tres emprendimientos escogidos para el estudio: la Asociación Mano de Tigre, El Descanso y El Rincón Ecológico de Térraba. En los lugares las entrevistas se llevaron a cabo de manera en la que el grupo de esta investigación llevó una guía con preguntas puntuales, pero a la hora de su ejecución fue una conversación entre los líderes de la comunidad y el grupo.

Guía de entrevista:

1. ¿Cuáles son los principales servicios turísticos a ofrecer?

2. ¿Cuáles son las principales actividades culturales/festividades que se realizan en la zona?

3. En cuáles de ellas ¿pueden participar personas externas a la comunidad?

4. ¿Cuáles son los impactos que han percibido del turismo?

5. ¿Creen que tienen limitantes en el desarrollo del turismo?

6. ¿Cuáles considera usted que son esas limitantes?

7. ¿Cómo cree usted que se puede solucionar las limitantes que se les presentan? 
Guía de observación participante

1. Escenario: ambiente físico, características espaciales, geográficas, formas, etc.

2. Personajes: actores que intervienen.

3. Actitudes de los actores.

4. Gestos y manejos del cuerpo.

5. Vestimenta.

6. Lo que se habla o calla.

7. Las interacciones entre actores o grupos.

Escenario: Comunidad de Bröran Térraba en Costa Rica. Cantón de Buenos Aires, provincia de Puntarenas. Se realizó el proceso de observación en las cabañas de alojamiento El Descanso, Asociación de Mujeres de Mano de Tigre y El Rincón Ecológico Térraba con el recorrido de senderos que son parte de la oferta turística actual. Todas las locaciones de turismo tienen una particularidad: se encuentran en un ambiente natural y las edificaciones son un conjunto entre lo tradicional y propio de ese pueblo y lo moderno utilizado en casas comunes.

Las personas entrevistadas fueron: Jeffrey Villanueva, Asdrúbal Rivera Villanueva, Doña Elides Rivera Navas, Don Paulino Nájera Rivera y Paolo Nájera.

Criterios de selección de las personas entrevistadas: Con conocimiento amplio en cuanto a historia, turismo y cosmovisión en territorio Brörán/Térraba.

La atención y la información brindada cumplió de manera positiva las expectativas de la investigación y de conocimiento en el sentido humano para comprender otras realidades y formas de ver el mundo. 
Lo que se habla o calla en las entrevistas: se manifiesta en todas las conversaciones las razones de lucha en el territorio y lo que ha significado eso como un "progreso para que las personas puedan incursionar en proyectos que les permitan crecer económica, cultural y naturalmente".

Las interacciones entre actores o grupos: Se logra una relación en donde todos somos considerados como iguales, y se establece el respeto de ambas culturas. Así como también un intercambio positivo de información, donde la información recopilada y el producto de la investigación posteriormente fue devuelto a la comunidad.

Los sujetos de la investigación son indígenas, dueños o partícipes de los emprendimientos turísticos y pobladores de la comunidad Bröran, Térraba, Puntarenas, Costa Rica. Seguidamente se muestran las personas consultadas según su participación en los emprendimientos turísticos:

- El Descanso: Las entrevistas estuvieron dirigidas a Jeffrey Villanueva, Asdrúbal Rivera Villanueva y un grupo de mujeres pertenecientes a la comunidad.

- Asociación Mano de Tigre: Se realizó una entrevista a Doña Elides Rivera Navas, perteneciente a la asociación.

- Rincón Ecológico: La entrevista se realizó a Don Paulino Nájera Rivera y a Paolo Nájera. 


\section{RESULTADOS Y DISUSIÓN}

\section{RAÍCES HISTÓRICAS DEL CONFLICTO POR EL TERRITORIO INDÍGENA BRÖRAN}

El sur de Costa Rica no fue dominado totalmente por los españoles, convirtiéndose en un refugio para distintos grupos indígenas que sufrieron el impacto del proceso de colonización. Durante el siglo pasado la colonización de las tierras bruncas se llevó a cabo desde 1938 por la compañía bananera, por el Estado a través del Instituto de Tierras y Colonización y con la llegada de PINDECO y sus estudios de factibilidad y adaptabilidad en los 60 y 70 y su posterior producción Piñera a partir de los 80. En este siglo, el peligro reside no solo en la expansión de la producción a gran escala de la piña y la palma aceitera, sino también con la llegada del Instituto Costarricense de Electricidad (ICE) que pretendió la construcción del Proyecto Hidroeléctrico Diquís.

Recientemente, la lucha indígena en Costa Rica se inicia en los 80, en ese momento "se tenía que ser valiente para decir que era indígena" nos cuenta Pablo Sivar Sivas. En ese momento, él no tenía tanto conocimiento como lo tiene ahora, pero buscaba defender sus derechos. Si bien existe desde 1973 la Comisión Nacional de Asuntos Indígenas (CONAI), ha sido cuestionada por los mismos indígenas, inclusive denunciada ante organismos estatales por mal manejo de permisos de tierras para personas no indígenas.

\section{LEY INDÍGENA}

La secretaria del Comité de Naciones Unidas para la Eliminación de la Discriminación Racial ONU-OACDH 1211, encabezada por la Señora Gabriella Habtom, en Ginebra, Suiza el 21 de Julio del 2010 establece lo siguiente en relación a la ley indígena costarricense y las problemáticas existentes en el territorio indígena en Térraba Bröran.

12. A pesar de que Costa Rica aprobó la Declaración de la Organización de las Naciones Unidas (ONU) sobre los Derechos de los 
Pueblos Indígenas del 2007 y es parte de una serie de convenciones internacionales que garantizan los derechos de los pueblos indígenas, incluyendo el Convenio 169 de la Organización Internacional del Trabajo (OIT), su principal ley sobre los pueblos indígenas, sigue siendo la Ley Indígena de 1977. Esta ley, establece que los territorios indígenas (aquellas áreas tituladas a los pueblos indígenas que por lo general no abarcan el territorio tradicionalmente poseído) son inalienables, imprescriptibles, no transferibles y exclusivas para los pueblos indígenas. A pesar de tener esta garantía, la ocupación ilegal y masiva de las tierras indígenas es una práctica común en Costa Rica. En el Territorio Indígena Térraba, más del 88 por ciento está ocupado ilegalmente. La gran mayoría de estos territorios son ocupadas abierta e ilegalmente por no indígenas.

14. En 1982, la Ley Indígena fue modificada por el Código de Minería, el cual eliminó la co-propiedad de los pueblos indígenas y el Estado a los recursos del subsuelo. Esto convirtió al Estado el único propietario de todos los recursos del subsuelo en el país, incluyendo aquellos pertenecientes a los territorios indígenas. Esta toma de decisiones se dio de manera unilateral sobre los derechos de los pueblos indígenas los recursos del subsuelo se tomó sin ninguna consulta, debido proceso o compensación.

15. La Ley Indígena, nominalmente reconoce y protege las estructuras comunitarias tradicionales y sus procedimientos (u otras entidades escogidas libremente por los pueblos indígenas). Sin embargo, menos de un año después de haber sido adoptada esta ley, estas entidades indígenas fueron abolidas por el Decreto 8489 de 1978 y fueron reemplazadas por las Asociaciones de Desarrollo Integral ("ADI"), la forma de gobierno local utilizada en todo el país. Las ADIs son, por ley, entidades oficiales del Estado y las ADls indígenas "representan" $y$ gobiernan cada territorio indígena. Este es el caso a pesar de que estas son estructuras foráneas que no toman en cuenta las tradiciones y costumbres de los pueblos indígenas, en muchos casos son percibidas por la mayoría de los pueblos indígenas de no estar acreditadas, no son representativas y no rinden cuentas. También, este es el caso de la Comisión Nacional de Asuntos Indígenas ("CONAl"), la entidad Estatal encargada de coordinar las ADIs en los territorios indígenas. Como menciona el CERD en el 2007, la CONAI "no ha representado los 
intereses de los pueblos indígenas, y que, como lo reconoce el Estado Parte, en el pasado no ha cumplido sus funciones y tareas.

\section{LA TOMA DEL COLEGIO EN 2012-2013}

Dentro de la situación deficitaria de las instituciones de educación secundaria en la zona, las y los estudiantes tenían serios problemas asociados con el traslado a diario unos 15 kilómetros desde el territorio Brörán hasta colegio de Buenos Aires, la carencia de una clase de cultura indígena, profesores no indígenas, el racismo en la educación, entre otros. Es por ello que el pueblo se manifiesta y toma posesión del colegio entre 2012 y 2013, con el fin de solicitar al Ministerio de Educación Pública (MEP), distintas demandas.

Esta situación tuvo una duración de 10 a 12 días hasta que un grupo de personas no indígenas estuvieron en contra de la toma del Liceo y se presentaron a lugar con la intención de agredir a los indígenas. Los Bröran se mantuvieron pacíficos ante la amenaza. En este episodio, la policía, que se encontraba en la comunidad, fue cómplice de los no indígenas, ya que abandonaron la comunidad cuando vieron a la turba dirigirse hacia el Liceo. En el momento que empezó la agresión con piedras, los abogados de organizaciones de apoyo al grupo indígena hicieron que se presentaran más patrullas. En este enfrentamiento civil, los no indígenas amenazaron a varios Bröran, diciendo que iban a matarlos y arrastrarlos, para que aprendan. Al mermar la problemática dentro de la comunidad y dentro del estudiantado se puede ver el racismo en puestos del colegio. Ejemplo de ello, es que se presenta la situación del director del Colegio de Térraba, quien laboraba como conserje del colegio; sin embargo, gracias a la defensa de sus derechos y divulgación de su capacidad y preparación profesional, al ganar la lucha, fue ascendido a su puesto actual (Asdrúbal Rivera Villanueva, indígena Bröran, conversación personal, 2018).

El Sistema Educativo ha tratado de mejorar y mediante un decreto del MEP se ha logrado que haya dos horas de Idioma y Cultura, pero sólo en educación primaria. 


\section{ETNOTURISMO EN TERRITORIO INDÍ- GENA BRÖRAN}

En esta sección se llevará a cabo una descripción no comparativa de la oferta turística de la comunidad Térraba, donde se podrá demostrar la importancia de las actividades turísticas desarrolladas por cada uno de los emprendimientos.

\section{A. LA ASOCIACIÓN MANO DE TIGRE}

Según Quesada (2014) la Asociación de mujeres indígenas Mano de Tigre de Térraba

es una organización que nace en los años 90 con la necesidad del momento que las mujeres indígenas del Territorio pudieran conocer sus derechos sociales, económicos, educativos y participativos en la toma de decisiones e incidencia política efectiva en los asuntos que conciernen a la población y en particular a ellas mismas.

A partir del año 2003 se consolida con personería jurídica, en este otro momento es ya para buscar fortalecimiento en lo económico que beneficie a las mujeres y sus familias. Así es que en la actualidad cuenta con proyectos de etnoturismo, artesanía, gastronomía cultural del pueblo Térraba, también se cuenta con un taller de costura donde se elabora ropa tradicional para mujeres y hombres.

Esta organización participa activamente en el mejoramiento de la salud en la comunidad, es así que desarrolla un programa de medio ambiente que consiste en cuatro áreas, reciclaje, educación ambiental, rotulación y siembra de árboles en áreas protegidas.

\section{$\underline{\text { Servicios Turísticos }}$}

El proyecto Mano de Tigre (Dobón Órcuo) (Navas, 2015) nació de una necesidad, nos cuenta doña Elides, quien, de pequeña, iba con su mamá y su hermana a la quebrada de Veragua donde se dedicaban a pescar y atrapar camarones mientras su mamá sembraba arroz y maíz. Pero ellas no 
aprendieron a sembrar ya que su papá se encargaba de todo. Al fallecer, él le hereda a Doña Elides, un terreno que estaba sembrado de café. Con el paso del tiempo, un año después de la muerte de su mamá, hablando con su hermana decide iniciar con el proyecto. En ese momento ella trabajaba en una ferretería, otras mujeres y adultos mayores trabajaban en agricultura, pero no Is pagaban justamente a pesar de trabajar lo mismo que los hombres ( 6 horas de trabajo a las mujeres se les pagaba como si fuesen 3 horas). Cuando empezaron a llegar personas para analizar el problema del Proyecto Hidroeléctrico Diquís se generó mucho movimiento en la comunidad. Universitarios y gente de instituciones que llegaban al pueblo, pero se hospedaban en Buenos Aires, comían afuera o compraban en almacenes o supermercados. Entonces decidió aprovechar los recursos que tenía a mano, por ejemplo, la casa se convirtió de un espacio privado familiar a un lugar para recibir visitantes y la cocina se transformó en una cocina comunitaria. El siguiente paso fue invertir en la creación del rancho y la batería de baños. Para el 2018 es una asociación de 12 mujeres indígenas, que no solo se dedican al turismo, sino que trabajan otros ámbitos, por ejemplo, en la producción agrícola y piscícola. Ofrecen distintos tours, por ejemplo, a Bijagual, Laguna Karsi, Mano de Tigre. También tienen producción de machacas, camarones de agua dulce y cangrejo, "no todas las personas se pueden dedicar a Turismo", sostiene Doña Elides Rivera Navas.

Nos debemos cuestionar los indicadores de desarrollo, por ejemplo, el Índice de Desarrollo Humano, ya que, si en zonas indígenas hay pobreza, es porque se mide desde la visión eurocéntrica y desarrollista, porque como nos dice doña Elides, ¿cuál pobre tiene sembrado para comer? Es así como se busca cambiar la percepción de qué es ser pobre dentro de la comunidad, ya que el tema de seguridad alimentaria podemos agregar que existe la producción local, que ha sido la producción ancestral. Un ejemplo de esto es que algunas personas de Brörán no comen bananos que crecen dentro de sus propiedades porque eso es "de pobres". Pero, si se compra el banano en la pulpería, adquiere valor, por ende, ya no es "pobre".

Se debe buscar una integración entre comunidad y universidades, ya que antes se realizaban trabajos, pero no se les devolvía el documento. Debe ser un trabajo recíproco y que considere el punto de vista de los indígenas, porque ellos también pueden aportar a las políticas mundiales. 
SI bien a nivel economicista, se puede ver que es una de las zonas de pobreza en el país, hay que saber que existe una riqueza del territorio.

\section{Condiciones Organizativas}

Existen dificultades, como mujeres, a la hora de poder tener emprendimientos o mejoras económicas, "querer salir adelante, pero ser mujer, además de ser indígena" es algo que genera una limitante. Se buscó avanzar no solo en la lucha, sino en el desarrollo de la organización también. Esto porque la lucha contiene la parte cultural, la sostenibilidad ambiental y el trasfondo político en cuanto a gobernanza

Existen limitantes como el recurso económico, en el sentido de que no pueden acceder a créditos a pesar de que sí tienen capacidad de pago. Esta situación se presenta debido a la escasez de pruebas o record económico que puedan presentar ante las entidades correspondientes. Se han beneficiado de fondos que otorga por ejemplo el Ministerio de Cultura y otras organizaciones (Elides Rivera Navas. Conversación personal, 2018).

Con el Turismo existen impactos positivos y negativos, por ejemplo, el contacto con personas es positivo en el sentido de que se da a conocer la cultura, se mantiene viva, se aporta a la economía, se intercambian conocimientos; pero también se necesitan de reglamentos o condiciones para que haya una visitación exitosa en el sentido de respeto y convivencia. Existe uno para Mano de Tigre, esto con el fin de buscar un respeto a lugares tradicionales de alto valor espiritual, es "crear un atractivo pero que la gente no sobrepase su disfrute" por ejemplo el no bañarse desnudos en Quebrada Honda.

Otro impacto es el que se da a nivel tecnológico, y puede ser aprovechado para compartir lo que sucede en la comunidad, dar a conocer servicios y conectarse a nivel mundial. Para Doña Elides, "el turismo tiene dos caras y hay que decidir cómo afrontar esta situación, si buscando el dinero o buscando un equilibrio". 
A nivel del territorio, se ha dado una recuperación de la cultura Brörán y la Asociación Mano de Tigre ha trabajado en la identificación tradicional con el traje tanto para hombre como para mujer, la gastronomía y la agricultura. Entre el 2010- 2011, mediante Becas Taller pudieron investigar y desarrollar la utilización de los vestidos y camisas Brörán, que están emparentados con los trajes de los Tjer-di (Naso Teribes) y que son hechos por dos mujeres de la Asociación, doña Isabel y doña Aidé.

Este traje adquirió un nuevo significado en las manifestaciones de 2018 que se dieron contra el Plan Fiscal, ya que, en el bloqueo del puente de Térraba, ellas iban identificadas con su traje. Este plan no fue consultado con ninguno de los 8 pueblos originarios del país y la afectación es grande según estima doña Elides. Que se hayan manifestado sobre el puente reafirma que los límites del territorio inician ahí, y esta lucha va de la mano con la recuperación territorial que se está realizando, la administración de este y la gobernanza; es una muestra más de resistencia al P. H. Diquís. Además de que las hace visibilizarse y reafirmar su identidad como mujeres Brörán.

Esta visibilización tiene un sentido más amplio cuando se trata de combatir la violencia de género que puede estar implícita en la comunidad. Existe un debate de si la inequidad de género aparece marcadamente con la llegada de los españoles o si antes de la llegada ya existía. En algunos pueblos indígenas la mujer no puede ejercer ciertos cargos, realizar ciertas tareas e inclusive se ve como si fuera una servidora del hombre. En Brörán, la violencia provenía desde adentro de las familias y el machismo era validado por las mujeres, como dice Doña Elides "las mujeres callaban y las madres guardaban silencio". Un ejemplo de esto es que cuando se dieron los primeros bonos de vivienda en el territorio, no se otorgaban a mujeres solteras, siendo también una violencia ejercida desde las instituciones del Estado. Otro caso se daba cuando ellas como organización participaban de reuniones y sus opiniones no eran tomadas en cuenta y escuchaban la frase descalificadora: "eso lo dicen porque son mujeres". A pesar de todo esto, buscaron tener un empoderamiento socioeconómico que les permitiera tener más facilidades. Entre la década de 1990 y 2000 , las mujeres no estaban tan organizadas y no había acceso a los recursos que otorgaban las instituciones del Estado; en los siguiente 8 años, las mujeres se organizaron, pero seguía sin haber recursos, así 
que se decide empezar a capacitar a las mujeres con el Instituto Nacional de Aprendizaje (INA), en artesanías, poner precios y caracterizarlas.

Esto las llevó a tener un proceso de concientización como mujeres con el fin de hacer valer sus derechos, su visión y buscar la paridad que se ve en la cultura a nivel espiritual considerando que es "La madre tierra", "la madre naturaleza", "la mujer del agua". La mujer da la vida para que exista un pueblo, y en esto "los tiempos de las mujeres son distintos, son de ciclos" como nos indica doña Elides. Esta lucha las ha llevado a participar de espacios como la Alianza de Mujeres de Mesoamérica y el I Foro de Pueblos Indígenas en Nueva York.

La especificidad de su lucha se origina en el hecho de que son mujeres indígenas, cada pueblo es distinto y cada comunidad tiene condiciones diferentes. No puede meterse en el mismo grupo la lucha de género por derechos reproductivos, la búsqueda de reconocimiento identitario sexual o la lucha por el reconocimiento y validación de la mujer indígena. Esto es algo que las instituciones a veces no comprenden a la hora de hacer foros o atender necesidades.

Ahora su objetivo es fortalecerse como organización de mujeres, Asociación de Mujeres Mano de Tigre Indígenas de Térraba, buscando una gobernanza más justa, sin abusos de ningún tipo, sin ser herramienta de intereses externos, siendo independientes porque la gobernanza territorial indígena no puede estar ligada a ningún partido político ni al Estado no indígena.

\section{B. EL DESCANSO}

\section{$\underline{\text { Servicios Turísticos }}$}

Alrededor de El Descanso existe un bosque con plantas medicinales, frutas, tubérculos, aguacate, banano criollo y árboles de cedro, balsa, ron ron y cristóbal. Entre lo que se ofrece hay un sendero al Petroglifo Nöskua 
T’lalá, que quiere decir Abuelo Mayor, el cual según el arqueólogo Francisco Cordero, data de entre 1000 a 2000 años.

Nos cuentan que existen dos teorías sobre cómo se realizó este petroglifo. Una es la parte espiritual de "las piedras suaves" $y$ la otra es una que se repite en pueblo indígena de los huetares, sobre un líquido que tenía la capacidad para maraca la piedra. El Petroglifo tiene una espiral marcada, lo que representa una naciente de agua cercana, entre otras figuras. También se cuenta que existen esferas de piedra con petroglifos y que se han encontrado herramientas de piedra para marcarlas también. Se incorporó en un manual de ventas, en el cual están incluidas en un 99\% de las actividades que se ofrecen, con tiempos de operación y costos.

Se considera al turismo como una actividad económica que va de la mano con el movimiento indígena, en el cual se revitaliza lo indígena (Díaz, 2009), mediante la utilización de rótulos para dar a conocer el idioma. Esto es importante ya que es la continuación de saberes, la vivencia de ancestros y lo que ellos cuentan.

Se inicia un proceso de construcción de memoria histórica hace 30 o 25 años, que es totalmente una "Revolución Brörán" que se origina por la deforestación masiva en los 70 , el peligro de desaparecer culturalmente según lo dicho por el lingüista Adolfo Constenla y es con esto que se inicia una recuperación del lenguaje, que también va de la mano tomar en cuenta otros saberes ignorados.

\section{Condiciones Organizativas}

Actualmente dentro de la comunidad existen más de 60 profesionales de distintas áreas trabajando en su propio territorio, y alrededor de 6 o 7 organizaciones grupales clánicas. Según el artículo 6 del convenio 169 de la OIT, los pueblos indígenas deben ser consultados, en esto el pueblo Brörán ha logrado defender sus intereses mediante la celebración de consultas. 
Los Brörán son el segundo pueblo con mayor exposición y participación en luchas. Entre las condiciones organizativas existen limitantes de carácter legales y económicas, por ejemplo, que los bancos no han creado una forma de financiamiento que pueda incluir a los indígenas.

Los emprendimientos Bröran buscan también el desarrollo de la soberanía alimentaria y la inclusión en el mercado internacional. Mediante el etnoturismo en el territorio, se crean fondos limpios que permiten crear infraestructuras pero que a su vez les permiten desarrollar acciones políticas, como la lucha por su territorio.

Actualmente, existe un trabajo que se está realizando con distintos profesionales, entre estos, un Premio Nobel Alternativo, Raúl Montenegro, profesor de la Universidad de Córdoba. Y se ha dado una recuperación de los diseños del traje tradicional cultural, con ayuda de los intercambios con los Teribe de Panamá.

Según lo que ellos cuentan, la política y el poder absorben a otros indígenas y hacen que traicionen a la comunidad. Por ejemplo, la Organización de la Asociación de Desarrollo permitió la entrada del Instituto Costarricense de Electricidad para desarrollar el Proyecto Hidroeléctrico Diquís. A algunos indígenas del territorio se les ha comprado el apoyo mediante sobornos, como "diarios" de comida o el pago de recibos, también ofreciéndoles empleos pero que serían "como picapiedras." A pesar de esto, las ADI en otros territorios han funcionado (por ejemplo, en Rey Curré). "El problema es que las ADI, son de DINADECO y por ende son las mismas figuras y el mismo reglamento que otras que se encuentran fuera de territorios indígenas, por ejemplo, en Escazú, esto porque no son figuras tradicionales de la cultura Brörán", expresan ellos. Aun así, la fuerza y el ánimo no se reducen.

No existe una competencia entre los 3 oferentes de servicio: Asociación Mano de Tigre, El Descanso, Rincón Ecológico; más bien existe un contacto el cual se traduce en beneficios para todos, ya que se envían y comparten grupos de personas ya sea para alimentación, hospedaje o tours. Esto debido a que son lugares con características diferentes. 
Los miedos que se podrían tener al iniciar los emprendimientos se han transformado y han mejorado la infraestructura, han salido en prensa nacional e internacional, han recibido visitas por parte de autoridades que han realizado los tours y se han hospedado como cualquier otra persona, ya que ellos brindan el mejor servicio a todos los que llegan.

\section{RINCÓN ECOLÓGICO}

\section{Servicios Turísticos}

Dentro de la oferta turística del Rincón Ecológico se podrá encontrar uno de sus principales tours que es una oportunidad para los visitantes de hacer un recorrido por medio de una caminata, disfrutando del paisaje y la naturaleza que rodea el lugar, con la oportunidad de observar variedad de especies de flora y fauna, principalmente aves.

El tour da inicio en el camino de mulas, se transita hasta llegar a la quebrada Bruin, que es el nombre del último cacique de los Brörán y es la palabra que designa la música del río, o el sonido que hace el agua al golpear las piedras. El sendero continúa por potreros ganaderos que han sido adquiridos por no indígenas. Finalmente, se llega a un portón que da entrada al bosque de Rincón Ecológico, donde existe un árbol de amarillón que sostiene una casa del árbol y es utilizada para la observación tanto de flora como de fauna.

El bosque se inició con pocas especies de árboles, alrededor de 4, sin embargo, con ayuda de un hermano de don Paulino Nájera, cuenta con más especies. Esto sirve para entender cómo el bosque ha mutado a través del tiempo y cómo el indígena no se entiende fuera del bosque. En él hay comida y medicinas, es su casa, en la cual existe una relación armoniosa. En palabras de don Paolo Nájera, el "bosque sin indígenas no existe" y podríamos agregar que el indígena sin bosque tampoco.

No existe el pago por Servicios Ambientales en territorio indígena, pero desde la montaña se puede ver el Parque Internacional La Amistad y cómo la frontera agrícola está muy cerca de los límites del parque, 
además de cómo fincas que cobran por estos Servicios Ambientales, son potreros ganaderos según se nos dice.

Según el artículo 3 de la Ley Indígena de 1977, los "no indígenas no podrán alquilar, arrendar, comprar o de cualquier otra manera adquirir terrenos o fincas comprendidas dentro de estas reservas". Lo que ha generado una base para la recuperación de territorio, otro de los factores es el hecho que hay lugares sagrados siendo pisoteados por ganadería, también las fuentes de agua se ven contaminadas.

El Índice de Desarrollo Humano coloca a cantones con población indígena en los últimos puestos, por ejemplo, Talamanca. En el caso de Térraba, que pertenece al cantón de Buenos Aires, en el 2016, se ubicó en el puesto 70. Esto se traduce para Paolo, como que la "existencia de la población indígena es un factor sistémico de la pobreza", según la visión eurocéntrica desarrollista. Sin embargo, esto se contrasta con lo que hemos escuchado de primera mano en las comunidades que visitamos como Kéköldi, Yorkin, Shuabb y Térraba, donde los indígenas no se identifican como pobres ya que tienen territorio y productos agrícolas.

\section{Impactos del turismo}

El turismo es visto como un generador de ganancia económica y sociocultural. En el proyecto Rincón Ecológico se debió plantear el problema sobre qué tipo de turismo se quería realizar en el territorio, entre "piscinas versus bosques" y se eligió el último. En el proceso han tenido contacto con turistas de distintas nacionalidades que buscan ese tipo de turismo, especialmente franceses y holandeses. Caso contrario se da en otras culturas, por ejemplo en la Maleku, donde la fetichización y mercantilización se ha realizado porque existen turistas que "quieren ver indígenas en taparrabos".

En cuanto al tipo de turismo que se ha desarrollado en el Pacífico sur de Costa Rica ha sido de turismo de sol y playa, lo que contrasta con las iniciativas en el territorio Brörán/Térraba. 
Existe una búsqueda incesante para brindar un mejor servicio, con un trato al cliente adecuado, ya que ellos ven que esto se refleja en más y mejor pago. Sin embargo, saben que el turismo muchas veces es elitista, que hace que la "gente pobre no tiene chance de esparcirse". Esto se da por el planteamiento neoliberal de vender, no pensando en el ambiente, sino cuánto dinero se puede obtener de las operaciones. Podemos decir que no existe una sostenibilidad, y que si existe es porque todo pasa por el discurso, como indica Paolo Nájera, y agrega que desde el mercado "todos tienen derecho a todo, pero no todos tienen dinero".

En el territorio hay un proceso de lucha por la soberanía alimentaria, según Paolo Nájera, nuestro entrevistado y guía, desarrollándose por medio de los botánicos de la cultura, los Awá, y desde el conocimiento técnico y académico con Luis Poveda, conociendo cuáles son plantas para la alimentación. Este proceso va acompañado de buscar una producción agrícola orgánica, que provee mayor rendimiento. Estos procesos se basan en la fijación de nutrientes y es una propuesta, le hace frente al cambio climático. Se trata, que desde el ser indígena, las prácticas contrarias a la conservación y a la diversidad biológica, desaparezcan de la mano de criterios técnicos que se basan en la agroecología.

También se busca que exista una economía interna en la comunidad, en vez de que los productores saquen sus productos, los vendan a los habitantes del territorio y esto ayudaría a reducir la huella ecológica y a reducir los costos por concepto de transportes y almacenamiento. Aun así es una gran mayoría de las personas que sacan su producto. Existen 15 técnicos de los cuales solo 2 trabajan en las comunidades dentro del territorio; los demás trabajan afuera para fincas u hoteles. Es necesario que se empiece a generar interés en regresar a la comunidad y que se establezcan prácticas técnicas de mejoras, por ejemplo, el no fumigar con agrotóxicos, se puede traducir para el agricultor en que va a gastar más si lo hace con agroquímicos. Se trata de que mediante aspectos ambientales que ellos conocen, no se vaya a perder todo un semestre de cultivos por un error, en palabras de Paolo: "toca echar el hombro a la gente que no lo hace porque quiere, sino porque no saben".

Existe "negación de ser un país agrícola" en Costa Rica, según indica Paolo. Pero para él, lo importante es el valor agregado que se le pueda dar al turismo mediante la práctica agroecológica. Aunque para él lo difícil es 
el prejuicio que existe en torno a los agricultores, por ejemplo, que son sin estudios, sin oportunidades y que por eso se dedican a la tierra, la cual es algo sucio que no debe tocarse si uno tiene oportunidad de estudiar y tener una carrera. Pero, ¿cómo se siembra un frijol o un maíz? es cuestión de seguridad alimentaria que no brinda una carrera.

Algunas limitantes son la falta de apoyo técnico, por ejemplo, en el idioma, ya que hay muy pocas personas que hablan inglés o francés. También el no acceso a créditos, que es una problemática que viene de los bancos, ya que sí existe capacidad de pago, como nos dice Paolo primero; y luego doña Elides lo reafirma. Mayoritariamente, el apoyo económico proviene de la cooperación extranjera, el problema es que si no se sabe realizar el formato de los distintos proyectos de cooperación no se puede participar y el segundo problema es la mala gestión de los distintos proyectos, lo que dice Paolo es que "no existe una administración correcta del dinero por parte de algunos indígenas". Otros limitantes del aspecto técnico son: conocimiento botánico, la falta de capacitación para guías turísticos y en cuanto en administración de los negocios.

Ventajas: El bajo impacto ambiental del turismo en la zona, los precios cómodos.

Además, se cree que es mediante las acciones que se puede lograr una sensibilización, sin ser solo personas que se quejan y no hacen nada respecto al tema. Ejemplos de ello son las fincas recuperadas de Crún Shürin (Tierra de Venado) en la cual se desarrolló durante 100 años explotación ganadera; y San Andrés, donde ahora se da un cambio en el uso de tierra, mediante agricultura y siembra de peces machaca. Con ello se busca que haya venta de productos agrícolas para que exista mayor liquidez dentro de la comunidad. Estos proyectos tienen como finalidad la mejora del territorio, porque nos dice Paolo que "la tierra recuperada se cuida y se quiere, no es para mí." 


\section{RELACIÓN DE LOS EMPRENDIMIENTOS CON LA GESTIÓN DEL TURISMO SOSTENIBLE}

En el territorio Térraba se encuentran 2 mil personas, según datos de Asdrúbal Rivera, los cuales, por medio del proceso de transculturación según Paolo,

Existen algunos riesgos que tienen mayor impacto que el turismo, por ejemplo, la creación de la Represa Hidroeléctrica (PH DIQUÍS) o el mismo sistema educativo costarricense, que no incluye completamente el conocimiento indígena y su propio sistema. Otras de las amenazas son la población no interesada en la tradición (Paolo Nájera, conversación personal, 2018).

Anuentes a este proceso, los turistas no son una gran amenaza para la comunidad, ya que el modelo de turismo que se ha buscado implementar hace que las personas que les visitan sean aún más sensibles y respetuosas ante su cultura y cosmovisión. Por ende, este no es un sitio donde se busca un ambiente de fiesta como se da en algunas playas, como en Jacó, en el pacífico central de Costa Rica. Y de esta manera es posible evitar la mentira de la mercantilización.

Por otra parte, la comunidad es consciente de que la mejor manera de evitar la pérdida de su cultura es por medio de una formación Brörán, la cual se imparte desde pequeños, no solo en la escuela con las dos horas de Idioma y cultura, sino desde sus hogares y con el aprendizaje en el bosque.

Del mismo modo, otro aspecto importante a destacar es cómo han logrado manejar su problemática territorial ante los visitantes, cuenta Paolo, que no se cuenta sobre la lucha de territorio a los turistas, ya que se cree en la diferenciación de espacios. Sólo si alguien pregunta se entra en el tema, esto con fin de no problematizar la tierra. 


\section{CONCLUSIONES}

Acorde al problema de investigación planteado en relación a las condiciones organizativas de las iniciativas de turismo que operan en la comunidad Bröran - Térraba y su relación con la gestión del turismo sostenible en sus territorios 2018, se identificó lo siguiente:

La reflexión en torno a las condiciones organizativas que presentan los emprendimientos turísticos la Asociación Mano de Tigre, el Descanso y Rincón Ecológico, en la comunidad Brörán - Térraba, se presentan condiciones similares en los tres emprendimientos y es así como el factor económico se identifica como la limitante más clara. Con esto se hace referencia al poco acceso a créditos.

Se concluye, por medio de la Identificación de las organizaciones indígenas locales, su relación con la gestión del turismo sostenible, dado que se ha realizado un gran esfuerzo por propiciar el desarrollo de la comunidad, la protección del medio ambiente y el patrimonio cultural que les rodea, esto con el fin de generar una sensibilización sobre el tema y los recursos necesarios para continuar ejecutando las acciones turísticas.

Del mismo modo, se observó cómo los emprendimientos etnoturísticos tienen segmento de mercado definido, esto por las condiciones presentes en el territorio las cuales son ventajas competitivas que se presentan a la hora de poder ofertar sus productos.

Se reconoció al territorio indígena Brörán como ejemplo en la lucha por sus derechos, por la permanencia de su cultura y la reapropiación de su territorio. 


\section{BIBLIOGRAFÍA}

Asamblea Legislativa de la República de Costa Rica (29/11/1977 1977) Ley Nº172 Ley Indígena. Diario Oficial La Gaceta. San José, Costa Rica.

Boege, E. (2008). El patrimonio biocultural de los pueblos indígenas de México: hacia la conservación in situ de la biodiversidad y agrodiversidad en los territorios indígenas (No. Sirsi) (97896803854).

Díaz, G. (2009). Identidad en la comunidad indígena de Térraba: un caso de revitalización. Cuadernos de Antropología No.19, 123140, 2009.

Dittel, L. (2015). Analizan conflicto de tierras en Diquís y Salitre. Hoy en el Tec. Obtenido: https://www.tec.ac.cr/hoyeneltec/2015/10/21/analizan-conflicto-tierras-diquis-salitre

Gutiérrez de Calderón y Attard, J. R. (2005). Turismo y ocio: La ocupación del tiempo libre. En: Turismo y patrimonio en Castilla-La Mancha. Valdepeñas, Ciudad Real. UNED.

Guzmán Chávez, M. G. (2012) De las antropologías del mundo a la ecología política del turismo. En: Turismo y antropología: miradas del Sur y el Norte. Alicia Castellanos Guerrero y Jesús Antonio Machuca (coordinadores). México. Universidad Autónoma Metropolitana y Juan Pablos Editor. Págs. 39-68.

Habtom, G. (2010). La Situación del Pueblo Indígena Térraba de Costa Rica: Una Solicitud para Consideración bajo el Procedimien- 
to de Alerta Temprana y Acción Urgente del Comité de Naciones Unidas para la Eliminación de la Discriminación Racial (77 Sesión). Comité de Naciones Unidas para la Eliminación de la Discriminación Racial. Ginebra, Suiza. ONU-OACDH.

Hurtado, P. Enero, 2015. Cuaderno de Trabajo de los Participantes. Gestión de Turismo Sostenible. SINAC

Instituto Costarricense de Turismo. (2018). Divisas por concepto de turismo. Tomado de: https://www.ict.go.cr/es/documentos-institucionales/estad\%C3\%ADsticas/cifras-econ\%C3\%B3micas/ costa-rica/960-divisas-por-concepto-de-turismo/file.html

Instituto de Fomento y Asesoría Municipal, IFAM (1985). Atlas Cantonal de Costa Rica. San José, Costa Rica. Biblioteca Virtual en población. Centro Centroamericano de Población.

Instituto Nacional de Desarrollo Rural INDER (2010). Plan Nacional de Desarrollo Rural del Territorio Buenos Aíres - Coto Brus 2015 -2020. Recuperado de: https://www.inder.go.cr/territorios_ inder/region_brunca/planes_desarrollo/PDRT-Buenos-AiresCoto-Brus.pdf

Koontz, H. y Weihrich, H. (1998) Administración Una Perspectiva Global, 11ª. Edición, México, McGraw Hill Interamericana Editores

Lagunas, D. (2012) De la actividad al discurso: problemas en torno a la antropología del turismo. En: Turismo y antropología: miradas del Sury el Norte. Alicia Castellanos Guerrero y Jesús Anto- 
nio Machuca (coordinadores). México. Universidad Autónoma Metropolitana y Juan Pablos Editor. Págs. 15-38.

Marín, G.; García, A. y Daltabuit, M. (2012). Turismo, globalización y sociedades locales en la península de Yucatán, México. Gustavo Marín Guardado, Ana García de Fuentes y Magalí Daltabuit Godás (Coords.). El Sauzal (Tenerife, España): ACA y PASOS, RTPC. Colección Pasos Edita no. 7. Recuperado de: http:// www.pasosonline.org/es/colecciones/pasos-edita/41-numero-7-turismo-globalizacion-y-sociedades-locales-en-la-peninsula-de-yucatan-mexico

Monterroso Salvatierra, N. (2011) La insustentabilidad del turismo sustentable. En: Desarrollo insostenible. Gobernanza, agua y turismo. Jesús Arroyo Alejandre e Isabel Corvera Valenzuela (compiladores). Guadalajara, Los Ángeles, México. Universidad de Guadalajara, UCLA Program on Mexico, PROFMEX-WORLD, Juan Pablos Editor.

Navas, J. (2015). Dobón órcuo ác: La leyenda Térraba (Brörán) de mano de tigre. Universidad Estatal a Distancia. Obtenido de: https://www.uned.ac.cr/extension/extension-en-accion/ noticias/717-dobon-orcuo-ac-la-leyenda-terraba-broeran-de-mano-de-tigre

Organización Mundial del Turismo (OMT). (2018). OMT Barómetro 2018. La Importancia del Turismo. Tomado de:_http://media. unwto.org/sites/all/files/inf_whytourismmatters_v2-18_0.png 
Programa de Naciones Unidas para el Desarrollo-Costa Rica. (2017). La desigualdad en Costa Rica y el cumplimiento de la agenda 2030 para el desarrollo sostenible. Obtenido de: Programa de Naciones Unidas para el Desarrollo Costa Rica.

Programa Estado de la Nación. (2011). Estado de la Nación en Desarrollo Humano Sostenible. Reconocimiento y exigibilidad de los derechos de los pueblos indígenas en Costa Rica: una aproximación. Derechos de los pueblos indígenas en Costa Rica. Obtenido de: Publicación digitalizada/Programa estado de la nación. Censos 2011 Capítulo 7.

Quesada, A. (2014). Asociación de Mujeres Mano de Tigre Indígenas de Térraba. Sistema de Información Cultural de Costa Rica Sicultura. Obtenido de:_https://si.cultura.cr/agrupaciones-y-organizaciones/asociacion-de-mujeres-mano-de-tigre-indigenas-de-terraba.html

Ramírez Guerrero, G. (2015). La Gestión del Turismo Sostenible: el caso español. Cádiz, España. Universidad de Cádiz.

Rivera, J. (2013). Turismo Térraba. Asociación Cultural Indígena Teribe TÉRRABA. Obtenido de: http://terraba.org/es/home.html

Salazar, L.; Souza, J.; Cheaz, J.; et al (2001). La dimensión de participación en la construcción institucional. Serie Innovación para la sociedad Institucional. San José, Costa Rica: Proyecto ISNAR “Nuevo Paradigma”. 
Sánchez, I. (2014). "Empoderando a las mujeres, empoderando a la humanidad: jimagínalo!". Programa pequeñas donaciones CR. Obtenido de: http://www.pequenasdonacionescr.org/ es/noticias/empoderando-las-mujeres-empoderando-la-humanidad-imaginalo

Sánchez, T. S. (2016). Análisis de la iniciativa etnoturística de la Asociación para la Defensa de los Derechos Indígenas Teribes de Térraba (ASODINT), en el sur de Costa Rica. Heredia, Costa Rica. Trabajo final de graduación sometido a consideración del Consejo de Gestión Académica. Universidad Nacional.

Umaña, J. (09 de agosto de 2017). Guías indígenas de Talamanca invitan al turismo mundial a visitar su cultura tras obtener declaratoria oficial del ICT. Hoy en el Tec. Cartago, Costa Rica. En: https://www.tec.ac.cr/hoyeneltec/2017/08/09/guias-indigenas-talamanca-invitan-turismo-mundial-visitar-su-cultura-obtener-declaratoria

Zúñiga Bravo, F. G. (2012). El patrimonio biocultural frente a los procesos de apropiación turística y mercantilización como estrategia de desarrollo para el Totonacapan veracruzano. En: Turismo y antropología: miradas del Sur y el Norte (pp. 233266). Alicia Castellanos Guerrero y Jesús Antonio Machuca (coordinadores). México. Universidad Autónoma Metropolitana y Juan Pablos Editor. 